Advanced Materials Development and Performance (AMDP2011)

International Journal of Modern Physics: Conference Series

Vol. 6 (2012) 757-761

(C) World Scientific Publishing Company

DOI: $10.1142 / \mathrm{S} 2010194512004102$

\title{
THE EFFECTS ON HEAT TREATMENT OF SIC COATED / GRAPHITE PLATE BY RF SPUTTERING SYSTEM
}

\author{
SEUNG-HYUN MOON \\ Dong-Eui University, Busan, Korea \\ msh0924@lycos.co.kr \\ HAN-KI YOON \\ Dong-Eui University, Busan, Korea \\ hkyoon@deu.ac.kr \\ RI-ICHI MURAKAMI \\ The University of Tokushima, Tokushima, Japan \\ murakami@me.tokushima-u.ac.jp \\ TAE-GYU KIM \\ Pusan National University, Kyongnam, Korea \\ tgkim@pusan.ac.kr \\ SEUNG-YON CHO \\ National Fusion Research Institut, Daejeon, Korea \\ sycho@nfri.re.kr \\ IN-KYUN YU \\ National Fusion Research Institute, Daejeon, Korea \\ ikyu@nfri.re.kr
}

\begin{abstract}
Silicon carbide film was coated by RF sputtering system onto graphite plate substrate. Surface roughness of substrate was polished by wet polishing with sand paper, number of 3000 . RF power was $200 \mathrm{~W}$ in $0.4 \mathrm{~Pa}$ of argon gas. Deposition holding time was 3hours in $600{ }^{\circ} \mathrm{C}$ temperature. Specimens were heat treated by 1200,1400 and $1500{ }^{\circ} \mathrm{C}$ for 1 hour to research the effect of heat treatment on $\mathrm{SiC}$ coating layer. Atomic Force Microscope (AFM) was used to characterize the surface morphology and the Sq surface roughness. AFM was used to investigate the grain size and roughness of the surface of thin coating film. X-ray diffraction (XRD) was used for detecting the coated SiC thin film by thin film mode. FE-SEM was used to characterize the microstructure of $\mathrm{SiC}$ coating film.
\end{abstract}

Keywords: SiC coating, RF sputtering system, Atomic force microscope, Heat treatment effects 


\section{Introduction}

Silicon carbide $(\mathrm{SiC})$ is a low activation and the high temperature material. $\mathrm{SiC}_{\mathrm{f}} / \mathrm{SiC}$ composite is a candidate material of blanket in fusion reactors. Helium Cooled Solid Breeder (HCSB) Test Blanket Module (TBM) is designed to give the simulated performance for DEMO-relevant blanket ${ }^{1}$. Graphite pebble has been considered as a reflector material for neutron irradiation. During operation of fusion reactor, the graphite pebble has to endure the harsh environment of neutron irradiation. According to mechanical properties of graphite, the strength and hardness are not enough to endure the irradiation environment in fusion reactor.

$\mathrm{SiC}$ coating is considered as an ideal protective method in several industrial sectors because of the physical, chemical and mechanical properties, high thermal conductivity and enough strength to endure the neutron irradiation on fusion reactor ${ }^{2-4}$. It is a important reason that its characteristics of high melting temperature, high oxidation resistance at high temperature and relatively low thermal coefficient of expansion. $\mathrm{SiC}$ has been researched for a reinforcement material in other materials ${ }^{5-6}$.

In this study, the characteristics of $\mathrm{SiC}$ coating layer on graphite plate was researched. $\mathrm{SiC}$ coating layers were deposited by RF Sputter system. The specimens were heat treated by 1200,1400 and $1500{ }^{\circ} \mathrm{C}$ for 1 hour to research the effect of heat treatment on $\mathrm{SiC}$ coating layer. It is possible that $\mathrm{SiC}$ crystal growth on graphite substrate above $1100{ }^{\circ} \mathrm{C}^{6}$. We expected dendrite structures of $\mathrm{SiC}$ developed on the original SiC film by heat treatment above $1100{ }^{\circ} \mathrm{C}$. AFM and X-ray diffraction (XRD) were used to characterize the surface morphology and the $\mathrm{Sq}$ surface roughness. Field Emission Scanning Electron Microscope (FESEM) was used to observe the microstructure of SiC coating surface.

\section{Experiment}

The $\mathrm{SiC}$ coatings were deposited by $\mathrm{RF}$ sputtering from a $\mathrm{SiC}$ target onto graphite plating substrate at $600{ }^{\circ} \mathrm{C}$ temperature. The target size is 2 inch diameter while the substrate is $20 \mathrm{~mm}$ by $20 \mathrm{~mm}$. The graphite plate was polished with sand paper, number of 3000 , and cleaned by acetone and alcohol in an ultrasonic bath for $5 \mathrm{~min}$.

The vacuum chamber was evacuated below $4 \times 10^{-2} \mathrm{~Pa}$. Pure argon $(99.99 \%)$ was introduced into the vacuum chamber after the vacuuming. The argon flow meter was by $50 \mathrm{sccm}$ to keep the vacuum in $0.4 \mathrm{~Pa}$. The cylindrical chamber size is $450 \mathrm{~mm}$ diameter and $350 \mathrm{~mm}$ height. The distance between target and substrate was about $30 \mathrm{~mm}$. The RF power was $200 \mathrm{~W}$. The temperature of substrate was $600{ }^{\circ} \mathrm{C}$ and deposing time was 3 hours. The specimens were heat treated in vacuum chamber after the coating process. The heat treatment temperature were none-HT, 1200,1400 and $1500{ }^{\circ} \mathrm{C}$ for 1 hour.

The surface morphology and the Sq surface roughness of $\mathrm{SiC}$ coated specimens were carried out with an atomic force microscope system in contact mode. Only one probe was used for analyzing all specimens in order to avoid the modification in the process of measurements. The probe consists of a V-shaped silicon nitride level and an integral 
sharp tip. Both the level and tip are coated with gold. All the presented images are $1 \times 1$ $\mu \mathrm{m}$ square. The brightness contrast in the AFM images testifies the height of $\mathrm{SiC}$ particles. The Sq surface roughness was evaluated by using specific software. And the microstructure was observed with the FESEM for research the crystallization by the heat treatment on microstructure.

\section{Results and Discussion}

The roughness ( $\mathrm{Ra}$ and $\mathrm{Sq}$ ) of heat treated $\mathrm{SiC}$ coating layer is shown in figure 1 . The $\mathrm{SiC}$ coatings were deposited on graphite plate substrate and heat treated at different temperature for 1 hour. The AFM image of heat treated $\mathrm{SiC}$ coating layer is presented in figure 2. The temperatures of heat treatment were none-HT, 1200,1400 and $1500{ }^{\circ} \mathrm{C}$. Ra and $\mathrm{Sq}$ were decreased with increasing of heat treatment temperature. The surfaces were very smooth. The Ra and Sq roughness of no heat treatment surface were about 16.5 and $22.5 \mathrm{~nm}$. Ra and Sq roughness were decreased to about 5.5 and $7 \mathrm{~nm}$ after heat treatment at $1500{ }^{\circ} \mathrm{C}$.

In figure 2, it shows that the surface became smoother at high temperature heat treatment. The particles of surface at no heat treatment was composed no shape with holes. SiC coating layer was composed of ellipse shaped particles after high temperature heat treatment. The average diameter of these particles were about $100 \sim 300 \mathrm{~nm}$.

After $1200{ }^{\circ} \mathrm{C}$ heat treatment, the particles were composed of ellipse shaped and the average diameter was about $300 \mathrm{~nm}$. These particles grow not absolutely perpendicular to the substrate. In case of $1400{ }^{\circ} \mathrm{C}$ heat treatment, the particles became smaller than $1200{ }^{\circ} \mathrm{C}$. The average diameter was about $200 \mathrm{~nm}$. Ra and Sq roughness of SiC film were similar with the particles of $1200{ }^{\circ} \mathrm{C}$ heat treatment. But the particles of $1500{ }^{\circ} \mathrm{C}$ heat treatment were decrease to the average diameter about $50 \mathrm{~nm}$ and $\mathrm{Ra}$ and Sq roughness of surface were decreased to about 5.5 and $7 \mathrm{~nm}$. Furthermore, the shape of particle was changed to globular shape.

$\mathrm{SiC}$ layer was coated onto graphite plate by RF sputtering system in XRD results in figure 3. According to figure $3, \mathrm{SiC}$ peak list was not found on specimen before heat treatment. The Specimens after heat treatment show SiC peak list. SiC coating layer before heat treatment was amorphous. The $\mathrm{SiC}$ layer was re-crystallized by heat treatment.

Figure 4 shows the microstructure image by FESEM after heat treatment of SiC coating layer by RF sputtering method system with 50,000 times magnification. In the image of (a), no crystalline was shown, because the layer was amorphous before heat treatment. SiC coating layer was composed of thread shape in image of (b). The thin film was re-crystallized by high temperature heat treatment. The shape of SiC layer was changed to globular shape at 1400 and $1500{ }^{\circ} \mathrm{C}$ heat treatment. And the shape of $1500{ }^{\circ} \mathrm{C}$ was bigger than $1400{ }^{\circ} \mathrm{C}$. 


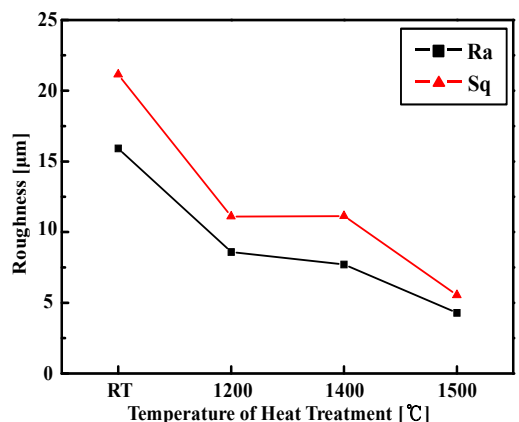

Fig. 1 The roughness of $\mathrm{Ra}$ and $\mathrm{Sq}$ of heat treated $\mathrm{SiC}$ coating layer

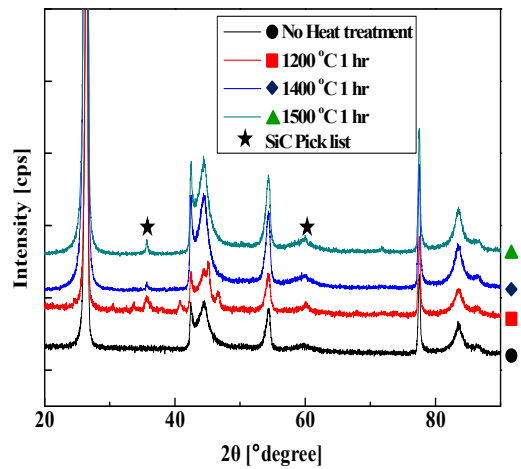

Fig. 3 XRD results of $\mathrm{SiC}$ coating layer
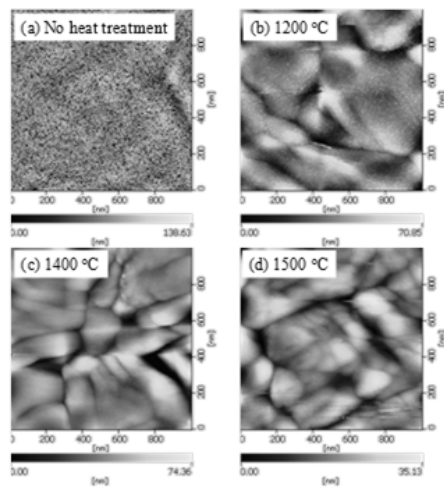

Fig. 2 The AFM image of heat treated SiC coating layer
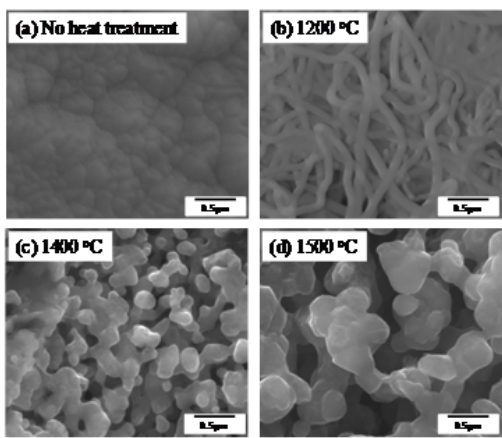

Fig. 4 The microstructure image of $\mathrm{SiC}$ coating layer

\section{Conclusion}

The characteristics of $\mathrm{SiC}$ coating layer by RF sputtering system was researched. Specimens were heat treated by no heat treatment, 1200,1400 and $1500{ }^{\circ} \mathrm{C}$ for 1 hour. AFM system and XRD was used to characterize the surface morphology and surface roughness. The microstructure was observed by FESEM.

In the results, sputtered $\mathrm{SiC}$ coating layer was re-crystallized by high temperature heat treatment. The roughness was decreased with increased temperature of heat treatment. The $\mathrm{Ra}$ and $\mathrm{Sq}$ roughness of no heat treated $\mathrm{SiC}$ coating layer were measured about 16.5 and $22.5 \mathrm{~nm}$ and decreased to about 5.5 and $7 \mathrm{~nm}$ after heat treatment at $1500{ }^{\circ} \mathrm{C}$. The particles of $1200{ }^{\circ} \mathrm{C}$ heat treatment specimen were composed of ellipse shaped and the average diameter was about $300 \mathrm{~nm}$ in AFM results. According as the increasing of temperature in heat treatment, these particles grow to globular shape. The amorphous $\mathrm{SiC}$ 
is coated by RF sputtering. The layer is re-crystallized by heat treatment in high temperature about 1400 and $1500{ }^{\circ} \mathrm{C}$. In the SEM image, the thin film was re-crystallized by high temperature heat treatment. The shape was thread shape but changed to globular shape at 1400 and $1500{ }^{\circ} \mathrm{C}$ heat treatment.

\section{Acknowledgments}

This research was supported by National R\&D Program through the National Research Foundation of Korea (NRF) funded by the Ministry of Education, Science and Technology \& Ministry of Knowledge Economy (2010EC001).

\section{References}

1. H.E.Gazzar, E.A.-Rahman, H.G. Salem, F. Nassar, Applied Surface Science 256, 2056-2060 (2010).

2. J. Yi, X. D. He, Y. Sun, J. of Alloys and Comp. 491, 436-440 (2010).

3. H. Tang, S. Tan, Z. Huang, S. Dong, D. Jiang, Surf. \& Coat. Tech. 197, 161- 167 (2005).

4. A.K. Costa, S.S. Camargo, Surf. and Coat. Tech. $163-164,176-180$ (2003).

5. A. Ordine, C.A. Achetea, O.R. Mattos, I.C.P. Margarit, S.S. Camargo Jr., T. Hirsch, Surf. and Coat. Tech. 133-134, 583-588 (2000).

6. R. Liu, C. Jhang, X. Zhou, and Y. Cao, J. Crystal Growth 270, 124 (2004). 